\title{
A novel mutation and first report of dilated cardiomyopathy in ALG6-CDG (CDG-Ic): a case report
}

\author{
Mohammed Al-Owain*¹,2, Sarar Mohamed ${ }^{+3}$, Namik Kaya ${ }^{4}$, Ahmad Zagal³, Gert Matthijs 5 and Jaak Jaeken6
}

\begin{abstract}
Congenital disorders of glycosylation (CDG) are an expanding group of inherited metabolic diseases with multisystem involvement. ALG6-CDG (CDGlc) is an endoplasmatic reticulum defect in N-glycan assembly. It is usually milder than PMM2-CDG (CDG-la) and so is its natural course. It is characterized by psychomotor retardation, seizures, ataxia, and hypotonia. In contrast to PMM2-CDG (CDGla), there is no cerebellar hypoplasia. Cardiomyopathy has been reported in a few CDG types and in a number of patients with unexplained CDG. We report an 11 year old Saudi boy with severe psychomotor retardation, seizures, strabismus, inverted nipples, dilated cardiomyopathy, and a type 1 pattern of serum transferrin isoelectrofocusing. Phosphomannomutase and phosphomannose isomerase activities were normal in fibroblasts. Full gene sequencing of the ALG6 gene revealed a novel mutation namely c.482A>G (p.Y161C) and heterozygosity in the parents. This report highlights the importance to consider CDG in the differential diagnosis of unexplained cardiomyopathy.
\end{abstract}

\section{Introduction}

Inborn errors of metabolism (IEM) account for only 5\% of all pediatric cardiomyopathy and $15 \%$ of patients with known causes. More than 40 different IEM involving cardiomyopathy exist, including energetic diseases with fatty acid oxidation defects and mitochondrial respiratory chain defects, organic acidurias, glycogen storage diseases, lysosomal storage disorders and congenital disorders of glycosylation [1]. Cardiomyopathy has been reported in PMM2-CDG (The novel CDG nomenclature is used ie the non-italicized gene symbol followed by: CDG [2,3]), ALG12-CDG (CDG-Ig), DK1-CDG (CDGIm) and COG7-CDG (CDG-IIe), as well as in patients with an unexplained CDG. Both hypertrophic and dilated cardiomyopathies have been described in CDG, with no common pattern observed in a particular CDG [4].

Congenital disorders of glycosylation (CDG) are a rapidly growing group of inherited metabolic disorders due to defects in the synthesis of glycans and their attachment to proteins and lipids [5]. They show a broad range of

\footnotetext{
* Correspondence: alowain@kfshrc.edu.sa

1 Department of Medical Genetics, King Faisal Specialist Hospital and Research Centre, Riyadh, Saudi Arabia

+ Contributed equally

Full list of author information is available at the end of the article
}

clinical manifestations and may be highly variable within the same subtype and even among affected siblings [6,7]. The method of choice for screening of these disorders is still isoelectrofocusing of serum transferrins (IEF) [8]. The $\mathrm{N}$-glycosylation defects can be divided in two groups: CDG-I caused by dysfunction of glycan assembly, and CDG-II, caused by abnormal glycan processing $[9,10]$. CDG-I patients usually show a type 1 serum transferrin IEF pattern, and CDG-II patients a type 2 pattern.

ALG6-CDG (MIM \#603147) is caused by defects in the ALG6 gene coding for Dol-P-Glc:Man9-GlcNAc2-P-PDol glucosyltransferase (glucosyltransferase 1). It is as a rule milder than PMM2-CDG (CDGIa) and is characterized by psychomotor retardation, axial hypotonia, seizures, ataxia, strabismus, feeding difficulties and a very low serum cholesterol and clotting factor XI [11-14]. Other reported features include retinal degeneration [10], deep vein thrombosis, and pseudotumor cerebri [15].

Here we report a Saudi child with ALG6-CDG and dilated cardiomyopathy caused by a novel mutation.

\section{Patient Report}

A 9 year old Saudi boy (Fig. 1) was referred for evaluation of psychomotor retardation, hypotonia and dilated cardi- 


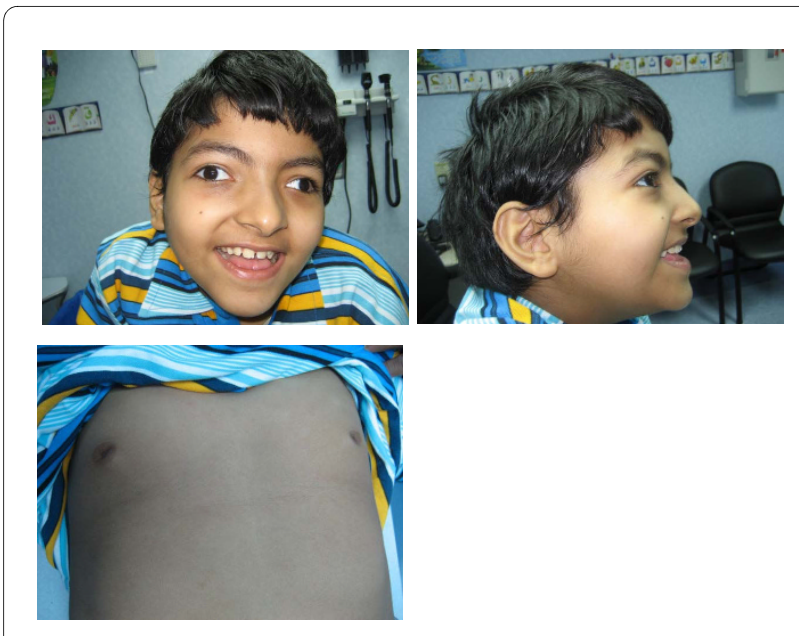

Figure 1 The patient at the age of 9 years. Note the low hairline, broad nasal bridge, hypetelorism, bilateral strabismus, large ears, wide mouth, thin upper lip, and widely spaced inverted nipples.

omyopathy. He was born at 40 weeks gestation after a normal pregnancy and delivery with a birth weight of 4.6 $\mathrm{kg}$. Hypotonia without feeding problems was noted in the neonatal period, bilateral alternating squint at two months of age, and hypokinesia at four months of age. At one year of age, he developed febrile seizures followed by afebrile partial epilepsy that responded well to carbamazepine. At three years of age, he presented with recurrent episodes of difficulty breathing and fatigability. Chest X-ray revealed cardiac enlargement with increased pulmonary vascularity. Echocardiography showed moderate dilatation and dysfunction of the left ventricle (LV). The end-systolic LV dimension was $3(1.7-2.5 \mathrm{~cm})$ corresponding to a Z-score of 4.3, while the end-diastolic LV dimension was $4.2(2.9-3.9 \mathrm{~cm})$ and the Z-score was 3.4 . The ejection fraction and ejection fraction shortening were slightly subnormal at $56 \%$ and $27 \%$, respectively. The interventricular septum thickness was normal. There was no mitral regurgitation and no pericardial effusion. These findings confirmed moderate cardiomyopathy of the dilated type. He was subsequently placed on captopril at a dose of $6.25 \mathrm{mg}$ three times daily that was continued for five years. Captopril was just recently weaned off with stabilization of the cardiac function. At the age of 6 years, he was not able to sit unsupported, was nonverbal and is completely dependent on the family for care. On physical examination at the age of 7 years, the child was wheelchair bound with severe mental retardation and no speech. His head circumference and weight were on the 50 centile. His height was on the 25 centile. He had brachycephaly, bilateral esotropia, coarse hair with double hair whorl, low anterior hair line, broad nasal bridge, widely spaced eyes, prominent large ears, short philtrum, wide mouth with a thin upper lip, small teeth, widely spaced inverted nipples, bilateral cryptorchidism, reduced muscle bulk and tone with axial hypotonia. Deep tendon reflex were difficult to elicit. Finger joints were hyperextensible but knees and hips showed limited joint extension. Routine laboratory investigations showed normal urinalysis, normal complete blood count, blood glucose, thyroid and kidney function tests, serum amino acids, lactate, acylcarnitine profile, and urine organic acids. Serum GOT was 37 (17-59 U/L), GPT 24 (21-72 U/ L). Cholesterol and clotting factor XI were not available. CSF examination was normal for cells, protein, glucose and lactate. Brain MRI revealed widening of CSF spaces and ventricular system with normal brain stem and cerebellum. EMG, nerve conduction velocity, funduscopy, hearing assessment and abdominal ultrasound were normal. Serum transferrin IEF showed a type 1 pattern. Phosphomannomutase 2, and phosphomannose isomerase activities were normal in fibroblasts. Molecular genetic testing diagnosed ALG6-CDG with a novel mutation namely c.482A $>$ G (p.Y161C).

The family history revealed that the patient was the fourth child born to healthy consanguineous parents, and he had two healthy siblings. His elder sister died at 7 years of age with a similar but more severe syndrome comprising microcephaly, deafness, blindness, severe psychomotor retardation and intractable seizures. She had no cardiac symptoms. She was investigated thoroughly for metabolic disorders including mitochondrial disorders and chromosomal abnormalities; however, no diagnosis was made at that time.

\section{Discussion}

ALG6-CDG is the second most frequently described Nglycosylation defect besides PMM2-CDG. At least 30 patients have been diagnosed [16]. Twenty one different mutations are listed in the Human Genome Mutation database http://www.hgmd.cf.ac.uk: sixteen point mutations, four deletions (including a large deletion enclosing the complete ALG6 gene), and one insertion. The c.998C $>\mathrm{T}$ (p.Ala333Val) mutation accounts for the majority of the alleles. The present patient is homozygous for a previously not reported mutation. The mutation found in this study is highly likely to be pathogenic for the following reasons a) PANTHER[17], POLYPHEN[18], and SIFT[19] bioinformatics tools all predicted that the change be deleterious and probably damaging, b) tyrosine in position p. 161 is phylogenetically conserved. His clinical presentation comprises the known features of ALG6CDG: axial hypotonia, moderate to severe psychomotor retardation, strabismus, epilepsy, without hepatomegaly, proteinuria, retinopathy and cerebellar hypoplasia. However, in addition, he shows dilated cardiomyopathy, a feature previously not reported in ALG6-CDG. The severity of the dilated cardiomyopathy in the present patient was 
moderate and required long-term cardiac treatment with captopril.

Cardiomyopathy (hypertrophic and dilated) has been reported in PMM2-CDG [20-25], in ALG12-CDG [26], in DK1-CDG [27], and in COG7-CDG [28], as well as in a number of patients with an unexplained CDG (CDG-Ix and CDG-IIx) $[4,21,29-33]$. The age of diagnosis of cardiomyopathy in reported cases ranged from the first week of life to 7 years of age, and in a few cases it was detected prenatally [2,25,31]. In addition, this is the first report of CDG from Saudi Arabia and it is likely that this condition is underdiagnosed in this region often due to poor access to appropriate metabolic and genetic testing.

In conclusion, we present the first case of ALG6-CDG associated with mild dilated cardiomyopathy due to a novel mutation in the ALG-6 gene. We feel from this report and along with previous reports that patients with unexplained (particularly syndromatic) cardiomyopathy should be investigated for CDG.

\section{Consent}

Written informed consent was obtained from the patient's parents for publication of this case report and accompanying images. A copy of the written consent is available for review by the Editor-in-Chief of this journal.

\section{Abbreviations}

CDG: congenital disorder(s) of glycosylation; IEF: isoelectrofocusing; IEM: Inborn errors of metabolism.

\section{Competing interests}

The authors declare that they have no competing interests.

\section{Authors' contributions}

MA, SM, AZ and JJ were involved in the clinical evaluation and follow-up of the patient, the data analysis and interpretation, and drafted the manuscript. GM carried out the molecular genetic studies and the interpretation of the results. NK assisted in performing the bioinformatics analysis and was involved in the write-up of the manuscript. All authors read and approved the final manuscript.

\section{Author Details}

'Department of Medical Genetics, King Faisal Specialist Hospital and Research Centre, Riyadh, Saudi Arabia, ${ }^{2}$ College of Medicine, Alfaisal University, Riyadh, Saudi Arabia, ${ }^{3}$ Department of Pediatrics, Saad Hospital, Al-Khobar, Saudi Arabia

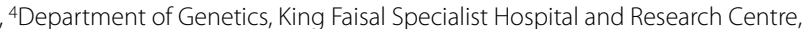
Riyadh, Saudi Arabia, ${ }^{5}$ Center for Human Genetics, University Hospital Gasthuisberg, Leuven, Belgium and ${ }^{6}$ Center for Metabolic Disease, University Hospital Gasthuisberg, Leuven, Belgium

Received: 30 December 2009 Accepted: 16 April 2010 Published: 16 April 2010

\section{References}

1. Cox GF: Diagnostic Approaches to Pediatric Cardiomyopathy of Metabolic Genetic Etiologies and Their Relation to Therapy. Prog Pediatr Cardiol 2007, 24(1):15-25.

2. Jaeken J, Hennet T, Freeze HH, Matthijs G: On the nomenclature of congenital disorders of glycosylation (CDG). J Inherit Metab Dis 2008 , 31(6):669-672.

3. Jaeken J, Hennet T, Matthijs G, Freeze HH: CDG nomenclature: time for a change! Biochim Biophys Acta 2009, 1792(9):825-826.
4. Footitt EJ, Karimova A, Burch M, Yayeh T, Dupre T, Vuillaumier-Barrot S, Chantret I, Moore SE, Seta N, Grunewald S: Cardiomyopathy in the congenital disorders of glycosylation (CDG): a case of late presentation and literature review. J Inherit Metab Dis 2009.

5. Westphal V, Schottstadt C, Marquardt T, Freeze HH: Analysis of multiple mutations in the hALG6 gene in a patient with congenital disorder of glycosylation Ic. Mol Genet Metab 2000, 70(3):219-223.

6. Jaeken J, Carchon $\mathrm{H}$ : Congenital disorders of glycosylation: the rapidly growing tip of the iceberg. Curr Opin Neurol 2001, 14(6):811-815.

7. Vodopiutz J, Bodamer OA: Congenital disorders of glycosylation-a challenging group of IEMs. J Inherit Metab Dis 2008.

8. Jaeken J, van Eijk HG, Heul C van der, Corbeel L, Eeckels R, Eggermont E: Sialic acid-deficient serum and cerebrospinal fluid transferrin in a newly recognized genetic syndrome. Clin Chim Acta 1984, 144(23):245-247.

9. Jaeken J: Komrower Lecture. Congenital disorders of glycosylation (CDG): it's all in it! JInherit Metab Dis 2003, 26(2-3):99-118.

10. Grunewald $\mathrm{S}$, Matthijs $\mathrm{G}$, Jaeken J: Congenital disorders of glycosylation: a review. Pediatr Res 2002, 52(5):618-624.

11. Grunewald S, Imbach T, Huijben K, Rubio-Gozalbo ME, Verrips A, de Klerk JB, Stroink H, de Rijk-van Andel JF, Van Hove JL, Wendel U, Matthijs G, Hennet T, Jaeken J, Wevers RA: Clinical and biochemical characteristics of congenital disorder of glycosylation type Ic, the first recognized endoplasmic reticulum defect in N-glycan synthesis. Ann Neurol 2000 47(6):776-781.

12. Hanefeld F, Korner C, Holzbach-Eberle U, von Figura K: Congenital disorder of glycosylation-lc: case report and genetic defect. Neuropediatrics 2000, 31(2):60-62.

13. Imbach T, Grunewald S, Schenk B, Burda P, Schollen E, Wevers RA, Jaeken J, de Klerk JB, Berger EG, Matthijs G, Aebi M, Hennet T: Multi-allelic origin of congenital disorder of glycosylation (CDG)-Ic. Hum Genet 2000, 106(5):538-545

14. Kahook MY, Mandava N, Bateman JB, Thomas JA: Glycosylation type Ic disorder: idiopathic intracranial hypertension and retinal degeneration. Br J Ophthalmol 2006, 90(1):115-116.

15. Sun L, Eklund EA, Van Hove JL, Freeze HH, Thomas JA: Clinical and molecular characterization of the first adult congenital disorder of glycosylation (CDG) type Ic patient. Am J Med Genet A 2005, 137(1):22-26

16. Sparks S: Congenital Disorders of Glycosylation Overview. 2009 [http:// www.ncbi.nlm.nih.gov/bookshelf/br.fcgi?book=gene\&part=cdg].

17. Thomas PD, Campbell MJ, Kejariwal A, Mi H, Karlak B, Daverman R, Diemer K, Muruganujan A, Narechania A: PANTHER: a library of protein families and subfamilies indexed by function. Genome Res 2003, 13(9):2129-2141.

18. Sunyaev S, Ramensky V, Koch I, Lathe W, Kondrashov AS, Bork P: Prediction of deleterious human alleles. Hum Mol Genet 2001, 10(6):591-597.

19. Ng PC, Henikoff S: SIFT: Predicting amino acid changes that affect protein function. Nucleic Acids Res 2003, 31(13):3812-3814.

20. Clayton PT, Winchester BG, Keir G: Hypertrophic obstructive cardiomyopathy in a neonate with the carbohydrate-deficient glycoprotein syndrome. J Inherit Metab Dis 1992, 15(6):857-861.

21. Imtiaz F, Worthington V, Champion M, Beesley C, Charlwood J, Clayton $P$, Keir G, Mian N, Winchester B: Genotypes and phenotypes of patients in the UK with carbohydrate-deficient glycoprotein syndrome type 1. J Inherit Metab Dis 2000, 23(2):162-174.

22. Di Rocco M, Barone R, Adami A, Burlina A, Carrozzi M, Dionisi-Vici C, Gatti R, lannetti P, Parini R, Raucci U, Roccella M, Spada M, Fiumara A: Carbohydrate-deficient glycoprotein syndromes: the Italian experience. JInherit Metab Dis 2000, 23(4):391-395.

23. Gehrmann J, Sohlbach K, Linnebank M, Bohles HJ, Buderus S, Kehl HG Vogt J, Harms E, Marquardt T: Cardiomyopathy in congenital disorders of glycosylation. Cardiol Young 2003, 13(4):345-351.

24. Aronica E, van Kempen AA, Heide M van der, Poll-The BT, van Slooten $H J$, Troost D, Rozemuller-Kwakkel JM: Congenital disorder of glycosylation type la: a clinicopathological report of a newborn infant with cerebellar pathology. Acta Neuropathol 2005, 109(4):433-442.

25. Malhotra A, Pateman A, Chalmers R, Coman D, Menahem S: Prenata cardiac ultrasound finding in congenital disorder of glycosylation type 1a. Fetal Diagn Ther 2009, 25(1):54-57. 
26. Kranz C, Basinger AA, Gucsavas-Calikoglu M, Sun L, Powell CM, Henderson FW, Aylsworth AS, Freeze HH: Expanding spectrum of congenital disorder of glycosylation Ig (CDG-Ig): sibs with a unique skeletal dysplasia, hypogammaglobulinemia, cardiomyopathy, genital malformations, and early lethality. Am J Med Genet A 2007, 143A(12):1371-1378.

27. Kranz C, Jungeblut C, Denecke J, Erlekotte A, Sohlbach C, Debus V, Kehl HG, Harms E, Reith A, Reichel S, Grobe H, Hammersen G, Schwarzer U, Marquardt T: A defect in dolichol phosphate biosynthesis causes a new inherited disorder with death in early infancy. Am J Hum Genet 2007, 80(3):433-440.

28. Wu X, Steet RA, Bohorov O, Bakker J, Newell J, Krieger M, Spaapen L, Kornfeld S, Freeze HH: Mutation of the COG complex subunit gene COG7 causes a lethal congenital disorder. Nat Med 2004, 10(5):518-523.

29. Horslen SP, Clayton PT, Harding BN, Hall NA, Keir G, Winchester B: Olivopontocerebellar atrophy of neonatal onset and disialotransferrin developmental deficiency syndrome. Arch Dis Child 1991, 66(9):1027-1032.

30. Hutchesson AC, Gray RG, Spencer DA, Keir G: Carbohydrate deficient glycoprotein syndrome; multiple abnormalities and diagnostic delay. Arch Dis Child 1995, 72(5):445-446.

31. Garcia Silva MT, de Castro J, Stibler H, Simon R, Chasco Yrigoyen A, Mateos F, Ferrer I, Madero S, Velasco JM, Guttierrez-Larraya F: Prenatal hypertrophic cardiomyopathy and pericardial effusion in carbohydrate-deficient glycoprotein syndrome. J Inherit Metab Dis 1996, 19(2):257-259.

32. Agarwal B, Ahmed A, Rushing EJ, Bloom M, Kadom N, Vezina G, Krasnewich D, Santi M: Congenital disorder of glycosylation-X: clinicopathologic study of an autopsy case with distinct neuropathologic features. Hum Pathol 2007, 38(11):1714-1719.

33. Iancu TC, Mahajnah M, Manov I, Cherurg S, Knopf C, Mandel H: The liver in congenital disorders of glycosylation: ultrastructural features. Ultrastruct Pathol 2007, 31(3):189-197.

doi: 10.1186/1750-1172-5-7

Cite this article as: Al-Owain et al., A novel mutation and first report of dilated cardiomyopathy in ALG6-CDG (CDG-Ic): a case report Orphanet Journal of Rare Diseases 2010, 5:

Submit your next manuscript to BioMed Central and take full advantage of:

- Convenient online submission

- Thorough peer review

- No space constraints or color figure charges

- Immediate publication on acceptance

- Inclusion in PubMed, CAS, Scopus and Google Scholar

- Research which is freely available for redistribution

Submit your manuscript at www.biomedcentral.com/submit
C) Biomed Central 